\title{
Modulation of 5-Aminolevulinic acid mediated photodynamic therapy induced cell death in a human lung adenocarcinoma cell line
}

\author{
Teijo MJ ${ }^{1,2}$, Diez B ${ }^{1,2}$, Batlle $A^{1}$ and Haydée Fukuda ${ }^{1,2 *}$ \\ ${ }^{1}$ Centro de Investigaciones sobre Porfirinas y Porfirias (CIPYP) - CONICET, Hospital de Clínicas José de San Martin, Argentina \\ ${ }^{2}$ Departamento de Química Biológica, Facultad de Ciencias Exactas y Naturales, Intendente Güiraldes 2160 - Ciudad Universitaria, Argentina
}

\begin{abstract}
Photodynamic therapy (PDT) is a cancer treatment involving the administration of a photosensitising drug which selectively accumulates in tumor tissue, followed by irradiation with appropriate wavelength light. It triggers photochemical reactions inducing reactive oxygen species (ROS) production with the consequent cellular damage, which ultimately leads to cell death. Porphyrins are the only photosensitizers (PSs) endogenously synthesized by means of administration of the biological precursor, 5- aminolevulinic acid (ALA). Several antioxidants and ROS scavenger agents: reduced glutathione (GSH), mannitol (Man), 1-tryptophan (Trp), ascorbate (Asc) and trolox (Trx), were assayed to determine their ability to modulate ALA-based PDT (ALA-PDT); it was performed on A549 human lung adenocarcinoma cells, by incubating with $1 \mathrm{mM}$ ALA for $3 \mathrm{hr}$ and followed by irradiation with or without $1 \mathrm{hr}$ pre-incubation with the modulators. They were previously tested for possible cytotoxicity/ photoactivity in concentrations ranging from 0.01 to $20 \mathrm{mM}$. The ratio between cell survival after ALA-PDT in the presence and in the absence of the scavenger agent (protection grade: PG) was determined, and the concentration showing no cytotoxicity/ photoactivity and providing the highest PG was used in the subsequent experiments. ALA-PDT alone induced a high percentage of apoptotic cell death $(98.4 \pm 3.5 \%)$ as revealed by acridine orange/ethidium bromide staining and AnnexinV-FITC/propidium iodide labelling. Pre-incubation with the modulators at their highest PG concentration significantly reduced apoptotic cells to $48.3 \pm 2.7 \%$ (Asc), $58.8 \pm 4.2$ (Trx), $78.5 \pm 3.1 \%$ (GSH), $64.3 \pm 1.6 \%$ (Man), $74.6 \pm 2.3 \%$ (Trp). ROS involvement in early cell death induction after ALA-PDT was tested by flow cytometry using the fluorescent probes dihydro-dichlorofluorescein diacetate (H2-DCFDA) and methoxyvinylpyrene (MVP) for detection of peroxides and singlet oxygen, respectively. ROS production increased after ALA-PDT (H2-DCFDA positive cells, control: $1.1 \pm 0.1 \%$; 10 min-PDT: $69.3 \pm 5.6 \%$; MVP positive cells, control: $0.65 \pm 0.35 \%$; 10 min-PDT: $83.5 \pm 1.9 \%)$. Asc prevented peroxide formation (H2-DCFDA positive cells: $50.7 \pm 2.8 \%)$ and mostly prevented singlet oxygen increase (MVP positive cells: $25.4 \pm 5.2 \%$ ) whereas Trx limited peroxides formation (H2-DCFDA positive cells: $20.8 \pm 0.5 \%$ ), but did not significantly affected singlet oxygen production (MVP positive cells: $73.6 \pm 3.4 \%$ ). Selective scavenger mediated protection against PDT-induced cell death, and direct detection of specific pro-oxidative agents, entail the strong involvement of ROS in ALA-PDT-mediated tumor eradication, suggesting that undesired photodamage to normal tissue might be attenuated by administration of antioxidant agents.
\end{abstract}

\section{Introduction}

PDT is a minimally invasive therapeutic procedure applied for obstructive, superficial and endoscopically accessible tumors as well as premalignant and non oncological disorders [1-3]. It involves the administration of a photosensitizing drug (PS) - often a porphyrin - which is selectively accumulated in malignant tissue. Subsequent irradiation with appropriate wavelength light triggers the excitation of the PS and the generation of ROS, mainly singlet oxygen, selectively destroying the target cell through the oxidation of cellular constituents, which damages plasma membranes and subcellular organelles [4,5]. The advantages of PDT over conventional therapies are the relatively high selectivity and low systemic toxicity, and so, PDT is being currently used for the treatment of many cancers such as bladder, brain, lung, gastrointestinal and gynaecological neoplasms, and also in dermatology and non-oncological disorders [6-14].

There are many different PSs, both synthetic and natural, most of them heterocyclic compounds with double bonds [4,5,15]. Among them, porphyrins are the only PS endogenously generated by the administration of its biological precursor 5-ainolevulinic acid (ALA), inducing the accumulation of Protoporphyrin IX (PpIX), which is a highly photosensitive compound [16], known to be responsible for the skin photodamage and cutaneous lesions in patients with Erythropoietic
Protoporphyria, a hereditary disorder caused by a deficiency in the enzyme Ferrochelatase involved in heme biosynthesis [17]. ALA and its ester derivatives have been successfully used to visualize and destroy malignant cells in experimental and clinical trials [18-23].

Conventional cancer therapy produces, in many cases, ROS which attack healthy cells and tissues leading as a consequence, to further damage and unintentional side effects. Antioxidants, owing to their free radical scavenger capacity, are able to decrease these adverse effects [24]; however, it must be taking into account that any antioxidant found to reduce toxicity of tumor therapy on healthy tissue has in addition the potential to decrease effectiveness of cancer therapy on malignant cells.

Tumor eradication by PDT involves several cell death types

Correspondence to: Haydée Fukuda and Alcira Batlle, Centro de Investigaciones sobre Porfirinas y Porfirias (CIPYP) - CONICET, Hospital de Clínicas, Viamonte 1881-10A, 1056-Buenos Aires, Argentina, Tel/Fax: (54) 11-45908346, E-mail: hfukuda@qb.fcen.uba.ar and batllealcira@yahoo.com.ar

Key words: photodynamic therapy, 5- aminolevulinic acid, reactive oxygen species, apoptosis, scavengers

Received: March 20 2016; Accepted: April 25, 2016; Published: April 29, 2016 
including necrosis, apoptosis and also autophagy [25-28]. These death pathways are not mutually exclusive; moreover, they can coexist and occur simultaneously under certain physiological or pathological conditions [29]. PDT causes cell death by irreversible photodamage to vital subcellular targets. The PS intracellular localization determines the primary site of photodamage, playing a key role on the cell death pathway. Since PSs rarely locate at nuclei, damage to DNA is limited. Generally, photoactive compounds localizing to mitochondria or endoplasmic reticulum promote apoptosis within a certain threshold of oxidative stress [28]. It has also been reported that certain PSs, such as, mono-L-aspartyl chlorine e6 (NPe6), cause an almost immediate disruption of the lysosomes after laser irradiation [30,31].

Apoptosis is a neatly regulated process, and the most extensive cell death pathway triggered by PDT. It is controlled by both intracellular and extracellular signals, ending in a characteristic sequence of morphological and biochemical changes for the systematic dismantling of the cell and preparation of the residual cell components, known as apoptotic bodies [26]. The cytotoxicity of PDT protocols, however, cannot be fully explained by the apoptotic response. With high PDT doses or PS localizing at the plasma membrane, necrosis is frequently observed [32]. This mode of cell death is represented by morphological signs such as vacuolization of the cytoplasm, swelling and breakdown of the plasma membrane resulting in an inflammatory reaction due to release of cellular contents and pro-inflammatory molecules. In addition, autophagy, characterized by the sequestration of cytoplasmic material in vacuoles for degradation by lysosomal enzymes, although a way of self-destruction, is not invariably a process of cell death; on the contrary, autophagy often protects against cell death removing damaged organelles or catabolising cellular macromolecules $[28,33]$.

In the present study we characterize the cellular response to ALAPDT in the human A549 lung adenocarcinoma cell line, and report on the ability of several antioxidant agents to prevent cell death after treatment and their implications in modulating PDT efficacy and ROS participation.

\section{Materials and methods}

\section{Chemicals}

ALA, $\mathrm{H}_{2}$ DCF-DA, MVP, dihydroethidine (HE), Rhodamine123 (Rh 123), Asc, Man, GSH, Succinil Acetone (SA) and Deferroxamine (Dfx) were obtained from Sigma Chem. Co. (USA). MitoTracker and LysoTracker Green were purchased from Mollecular Probes Inc, and Annexin V-FITC from Invitrogen (Argentina). All other chemicals used were of analytical grade.

\section{Cell line and cell culture}

The human A549 lung adenocarcinoma cell line (non-small cell lung cancer, NSCLC) was grown at $37^{\circ} \mathrm{C}$ in $5 \% \mathrm{CO}_{2}$ humidified atmosphere in Minimum Essential Medium (MEM) supplemented with $5 \%$ foetal calf serum (FCS), $80 \mu \mathrm{g} / \mathrm{ml}$ gentamicin and $2 \mathrm{mM}$ l-glutamine. To perform the experiments cells at densities from $5 \times 10^{4}$ to $1 \times 10^{5}$ cells $/ \mathrm{ml}$ were seeded in 24 or 6 -well plates, according to the assay.

\section{ALA-PDT treatment}

As a standard procedure, cells were allowed to grow until subconfluence, then, culture medium was replaced by serum free medium to avoid porphyrin externalisation [34], and incubated $3 \mathrm{hr}$ with $1 \mathrm{mM}$ ALA final concentration. Afterwards, cells were illuminated with two fluorescent lamps (Osram L 18W/765) emitting wavelengths over the range $400-700 \mathrm{~nm}$ with the highest radiant power at $600 \mathrm{~nm}$ $\left(0.4 \mathrm{~J} / \mathrm{cm}^{2}\right)$ and located at $21 \mathrm{~cm}$ from the plates. The percentage of viable cells after PDT was determined by the MTT (3(4,5-dimethylthiazol-2yl)-2, 5-diphenyltetrazolium bromide) assay [35].

\section{Modulators of porphyrin biosynthesis and antioxidants}

SA and Dfx were prepared at $20 \mathrm{mM}$ concentration, dissolved in distillate water and PBS, respectively. To assess a putative protecting effect of several antioxidant and scavenger agents (Trp, GSH, Man, Asc and Trx), they were dissolved in PBS and added to the cell culture 1 $\mathrm{hr}$ before ALA administration; then, incubation and irradiation were performed as described previously.

\section{Subcellular localization of ALA-induced PpIX}

Cells were seeded on coverslips at the bottom of 6-well plates and grown to subconfluence. After $18 \mathrm{hr}$ incubation with $1 \mathrm{mM}$ ALA, cells were loaded with $150 \mathrm{nM}$ MitoTracker Green or LysoTracker Green for $30 \mathrm{~min}$ at $37^{\circ} \mathrm{C}$. Coverslips were mounted on slides and examined with confocal microscope (Nikon C1, objective: 60x Plan Apo Oil NA $1.40)$.

\section{Mitochondrial and lysosomal damage after PDT}

Cells were grown on coverslips as mentioned above, and incubated with $1 \mathrm{mM}$ ALA during $2.5 \mathrm{hr}$; then, $150 \mathrm{nM}$ MitoTracker Green or LysoTracker Green were added and the incubation continued for 30 min. Plates were irradiated for $10 \mathrm{~min}$ and examined $1 \mathrm{hr}$ later under fluorescence microscopy (Olympus BX51) for organelle morphology.

\section{Toluidine blue and Hoechst staining}

Cells grown on coverslips were submitted to ALA-PDT as mentioned above and fixed $1 \mathrm{hr}$ after treatment in $4 \%$ formaldehyde for $20 \mathrm{~min}$ at $4^{\circ} \mathrm{C}$ (Toluidine blue staining) or $7 \mathrm{~min}$ in methanol at $-20^{\circ} \mathrm{C}$ and permeabilized with $0.1 \%$ Tritón X-100 in PBS (Hoechst staining). Coverslips were washed 4 times for $5 \mathrm{~min}$ with cold PBS. After washing once with PBS, $0.5 \%$ Toluidine blue or $40 \mu \mathrm{l}$ of $1 \mu \mathrm{g} / \mathrm{ml}$ Hoechst 33258 was added, and cells were observed under fluorescence microscopy (Olympus BX51) for nuclear morphology.

\section{Cellular morphology assessment with acridine orange and ethidium bromide double staining}

Acridine orange penetrates into living and dead cells emitting green fluorescence as a result of intercalation into double stranded DNA, and red-orange fluorescence after binding with single stranded DNA due to its accumulation in lysosomes. Ethidium bromide emits red fluorescence after intercalation into DNA of cells with altered membranes at late apoptosis stages or necrosis. Thus, the combination of these two fluorochromes allows distinguishing four cell states: living cells (green nucleus), early apoptotic cells (chromatin condensation, green nuclei), late apoptotic (orange and condensed or fragmented nuclei) and necrotic cells (uniform orange dyed nuclei). Briefly, $1 \mathrm{hr}$ after ALA-PDT cells were trypsinized, washed with PBS and resuspended at $1 \times 10^{6}$ cells $/ \mathrm{ml}$. Then, $2 \mu \mathrm{l}$ of the fluorochromes mixture $(50 \mu \mathrm{g} / \mathrm{ml}$ each) was added and cells examined under fluorescence microscopy (Olympus BX51). At least 200 cells were counted for each treatment.

\section{Phosphatidylserine exposure detection with annexin V-FITC labelling and propidium iodide staining}

$1 \mathrm{hr}$ after ALA-PDT cells were trypsinized, washed with PBS and 
resuspended at $2 \times 10^{6}$ cells $/ \mathrm{ml}$ in binding buffer containing $10 \mathrm{mM}$ HEPES/ $\mathrm{NaOH}, \mathrm{pH} 7.4 ; 140 \mathrm{mM} \mathrm{NaCl}, 2.5 \mathrm{mM} \mathrm{CaCl}_{2}$. Aliquots of 100 $\mu \mathrm{l}$ were incubated for $15 \mathrm{~min}$ at room temperature with $5 \mu \mathrm{l}$ Annexin V-FITC. Later, propidium iodide was added to a final concentration of $5 \mu \mathrm{g} / \mathrm{ml}$ and volume was completed to $500 \mu \mathrm{l}$. Samples were analyzed with a Partec PAS III flow cytometer.

\section{Reactive oxygen species production}

For ROS detection, cells from $24 \mathrm{hr}$ culture were trypsinized $1 \mathrm{~h}$ after ALA-PDT treatment and incubated $30 \mathrm{~min}$ in the dark at $37^{\circ} \mathrm{C}$ with one of the following ROS fluorescent detection probes: $10 \mu \mathrm{M} \mathrm{H}_{2}$ DCFDA ( $\lambda$ emission: $530 \mathrm{~nm}), 10 \mu \mathrm{M}$ MVP ( $\lambda$ emission: $465 \mathrm{~nm}), 2$ $\mu \mathrm{M}$ HE ( $\lambda$ emission: $461 \mathrm{~nm}$ ) or $10 \mu \mathrm{M} \mathrm{Rh} 123$ ( $\lambda$ emission: $534 \mathrm{~nm}$ ). Samples were analyzed with a Partec PAS III flow cytometer.

\section{Statistical analysis}

The values are expressed as means \pm standard error of the mean, and they are the average of three independent experiments run in triplicate. Data were analyzed with GraphPad Prism (GraphPad Software Inc., San Diego, CA, USA).

\section{Results}

\section{Response to ALA-PDT is light dose - dependent}

PpIX accumulated after incubation with increasing concentrations of ALA from 0.1 to $5 \mathrm{mM}$ for $3 \mathrm{hr}$ raised until a plateau at $1 \mathrm{mM}$, reaching $11.67 \pm 0.18 \mathrm{ng} / 10^{5}$ cells. At different incubation times, from 1 to $8 \mathrm{hr}$, PpIX levels kept linearly rising up to $29.89 \pm 1.45 \mathrm{ng} / 10^{5}$ cells. The amount of porphyrins released to the cell medium did not contribute significantly to the total porphyrin production. ALA did not produce considerable dark toxicity at any concentration or incubation time as verified by the MTT assay. In the absence of porphyrins, the most prolonged irradiation time used $(15 \mathrm{~min})$ did not alter the survival of the cells (data not shown). Therefore, the conditions for the subsequent PDT treatments were established at $1 \mathrm{mM}$ ALA final concentration and $3 \mathrm{~h}$ incubation. Once ALA-PDT was performed, cell viability was determined $1 \mathrm{~h}$ after treatment and it was found to decrease as irradiation time increased, reaching almost $90 \%$ cell death at $15 \mathrm{~min}$ and $50 \%$ at $7 \mathrm{~min}$ irradiation, determining this last value the $\mathrm{LD}_{50}$ for the cell line (Figure 1).

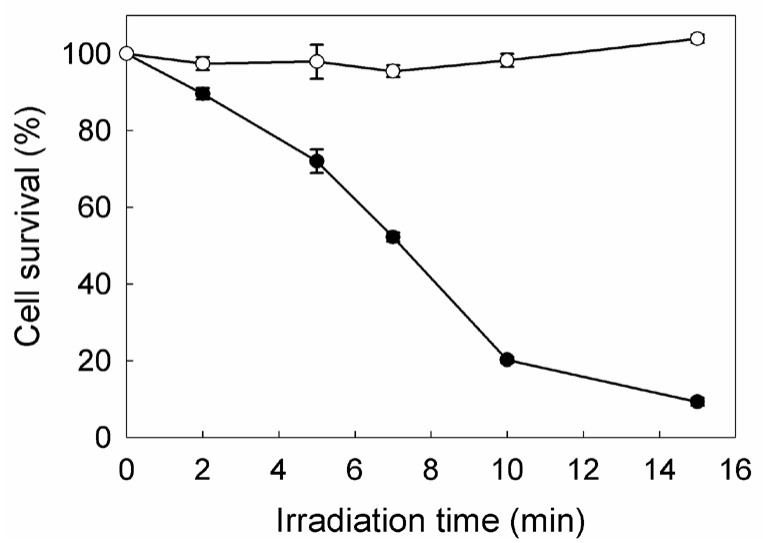

Figure 1. Effect of increasing irradiation time on cell survival. Cells were incubated for 3 $\mathrm{hr}$ in serum-free media with $(\bullet)$ or without (०) $1 \mathrm{mM}$ ALA, followed by irradiation with fluorescent lamp during different times; $1 \mathrm{~h}$ later MTT assay was performed. Bars: SE based on three independent experiments with three parallels in each.
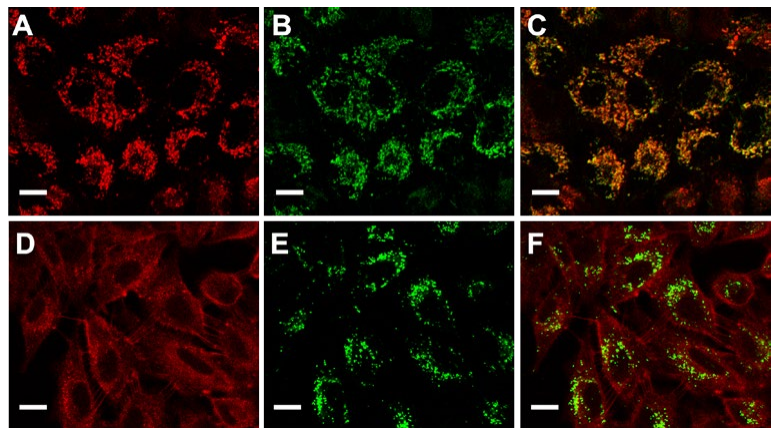

Figure 2. ALA- induced PpIX localization.

Fluorescent confocal images of cells incubated with ALA (A and D), ALA plus MitoTracker Green (B) or ALA plus LysoTracker Green (E) and the corresponding merging (C and F). Briefly, cells grown on coverslips were incubated for $18 \mathrm{hr}$ with 1mM ALA and then loaded with $150 \mathrm{nM}$ MitoTracker or LysoTracker Green, and visualized under confocal microscopy (Nikon C1, objective: 60x Plan Apo Oil NA 1.40; scale bar: $20 \mu \mathrm{m}$ ).

\section{ALA- induced PpIX accumulates in mitochondria}

PpIX distribution in the cells can be visualized by its own red fluorescence whereas mitochondria and lysosomes were visualized by means of the specific probes Mito Tracker and Lyso Tracker Green. Confocal images (Figure 2) showed that following incubation with ALA, the red fluorescence of PpIX co-localized with the green fluorescence of organelle probes only when visualizing mitochondria but not lysosomes.

\section{Cell and organelle morphology indicate apoptotic cell death after ALA-PDT}

We next examined morphological changes in ALA-PDT treated cells, as revealed by Toluidine blue and Hoechst staining by conventional and fluorescence microscopy respectively. Representative images are shown in Figure 3. Immediately after illumination, cells detached from the substrate. Severe damage to the membrane and nucleus after $7 \mathrm{~min}$ ALA-PDT can be seen, whith picnotic nucleus and a marked reduction in the cell size, together with a prominent membrane blebbing. As the irradiation time increased, it can be observed progressive detachment, rounding, membrane blebbing and nuclei condensation (Figure 3 panels $\mathrm{B}$ and $\mathrm{C}$ ) revealing morphological features of cells undergoing apoptosis. The highest PDT dose tested $(15 \mathrm{~min})$ produced a low percentage of membrane swelling consistent with necrotic features (Figure 3A).

Also double staining with acridine orange/ethidium bromide revealed high percentages of cells with chromatin condensation and membrane blebbing consistent with apoptosis, rising from $10.2 \pm$ $1.1 \%$ in untreated cells to $98.3 \pm 3.5 \%$ for 15 min ALA-PDT (Figure 3 panel D, Figure 4A). Membrane phosphatydil-serine externalisation is another apoptosis induction sign. Labelling with Annexin V- FITC/ propidium iodide staining allows distinguishing necrotic, and early and late apoptotic cells from viable ones. Consistent with acridine orange/ ethidium bromide results, the yield of apoptotic cells assessed by flow cytometry increased with irradiation time (Figure 3 panel E, Figure 4B) from $2.3 \pm 0.1 \%$ in untreated cells to $64.2 \pm 5.5 \%$ for 15 min ALA-PDT. At all time PDT doses, the percentage of necrotic cells remained low.

Forward (FSC) and side scatter (SSC) of light reflected by cells in a flow cytometer represent granularity and cell size, respectively. Apoptotic cells typically show a reduced cell size and increased granularity due to cell constriction and apoptotic bodies formation. Therefore, FSC-SSC plots complement Annexin/propidium iodide 


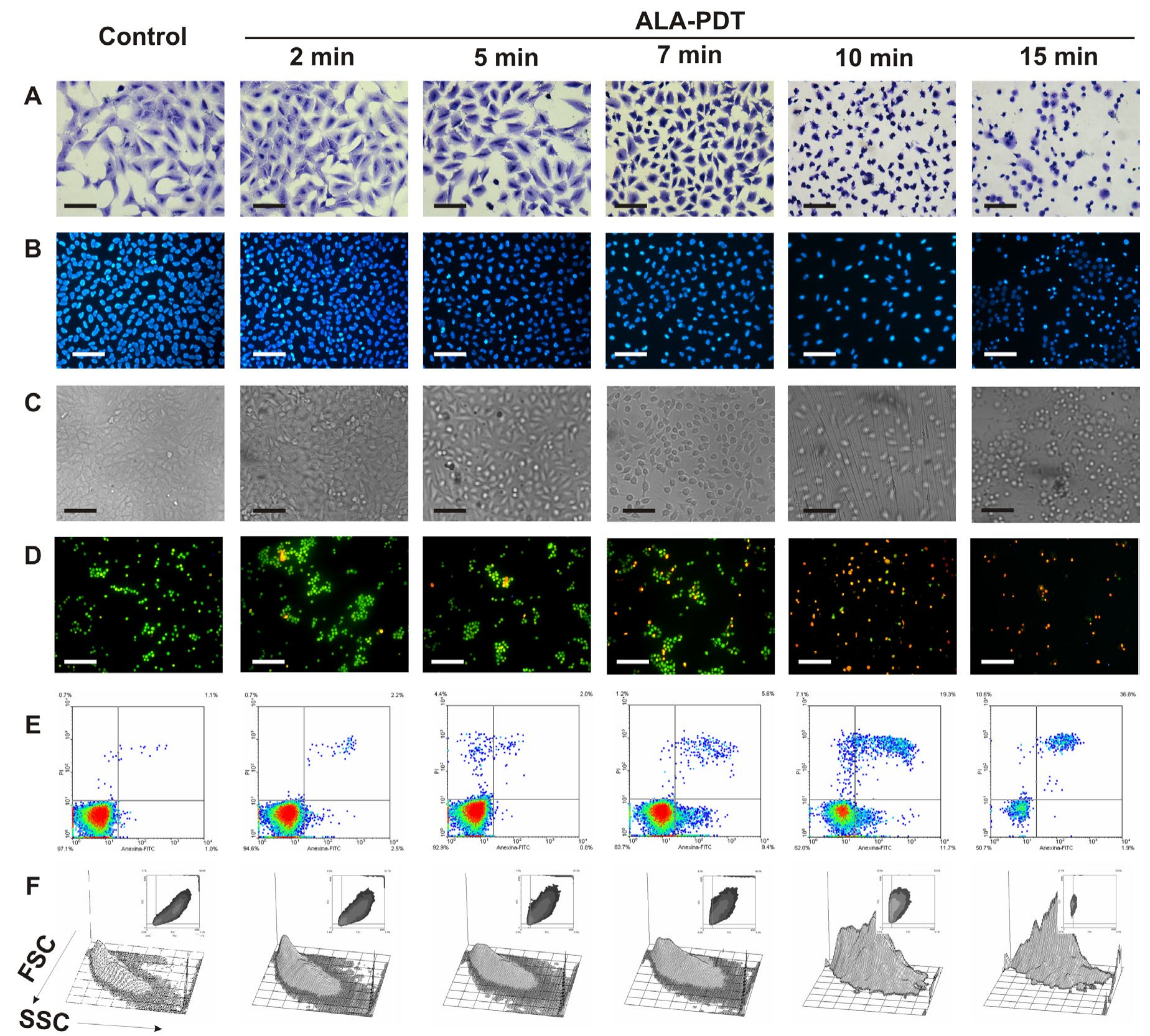

Figure 3. Changes in cell morphology at different time-dose ALA-PDT

Cells were incubated with $1 \mathrm{mM}$ ALA for $3 \mathrm{hr}$ and then irradiated 2, 5, 7, 10 and $15 \mathrm{~min}$. After $1 \mathrm{hr}$, cells still attached to coverslips were fixed and stained with Toluidine blue (panel A) or Hoechst (panels B and C) and visualized under conventional or fluorescence microscopy. In parallel experiments, cells were trypsinized and stained with acridine orange / ethidium bromide (panel D) and visualized under fluorescence microscopy, or labelled with Annexin V-FITC /propidium iodide (panel E) and analyzed by flow cytometry. Cell size and granularity were assessed by light scattering by flow cytometry (panel F). Scale bars for panels A, B and C: $100 \mu \mathrm{m}$ and for panel D: $150 \mu \mathrm{m}$.

plots with simultaneous morphological data. As can be seen in Figure 3 panel F, FSC-SSC plots show the progressive cell size reduction and increasing granularity consistent with the apoptotic process.

In order to assess organelle damage after ALA-PDT, cells were incubated and then irradiated in the presence of specific probes for mitochondria and lysosomes. In untreated cells, Mito and Lyso Tracker are taken up by polarized mitochondria or intact lysosomes respectively. After depolarization of mitochondrial membrane or lysosome disruption, the probes are released to the cytoplasm, showing uniform pattern of the fluorescence instead of that corresponding to the normal organelle localization and distribution. Therefore, these features are signs of damage to the organelles. In our case, $10 \mathrm{~min}$ irradiation time produced not only cell detachment but also the loss of the punctuate pattern for lysosomes and mitochondria observed in control cells (Figure 5). Although the fluorescence distribution after the irradiation was diffuse but not absolutely uniform, it is consistent with a marked externalization of the probes, indicating disruption of organelle integrity. 

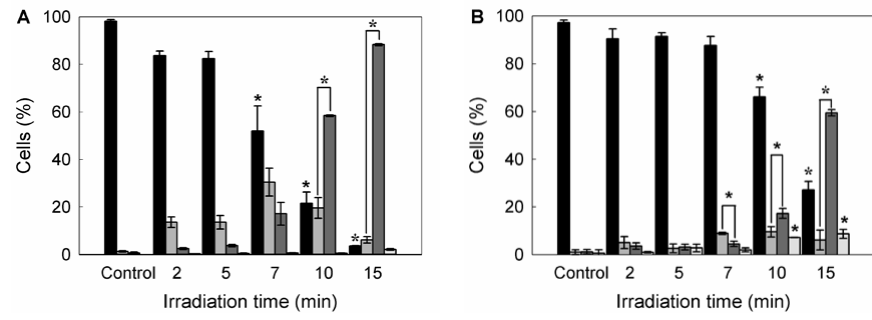

Figure 4. Quantification of viable, apoptotic and necrotic cells after different ALA-PDT time dose.

Once PDT was performed, $1 \mathrm{hr}$ after cells were trypsinized and stained with acridine orange/ ethidium bromide, and visualized and counted by fluorescence microscopy (A), or labelled with Annexin V-FITC /propidium iodide and analyzed by flow cytometry (B). Bar colors: black $\mathbf{m}$ : viable cells; dark grey $\mathbf{m}$ : early apoptotic cells; light grey $\mathbf{m}$ : apoptotic cells; white $\square$ : necrotic cells) $\left(*: \mathrm{p}<0.05 ;{ }^{*}: \mathrm{p}<0.01\right.$; significance respect to untreated control cells)
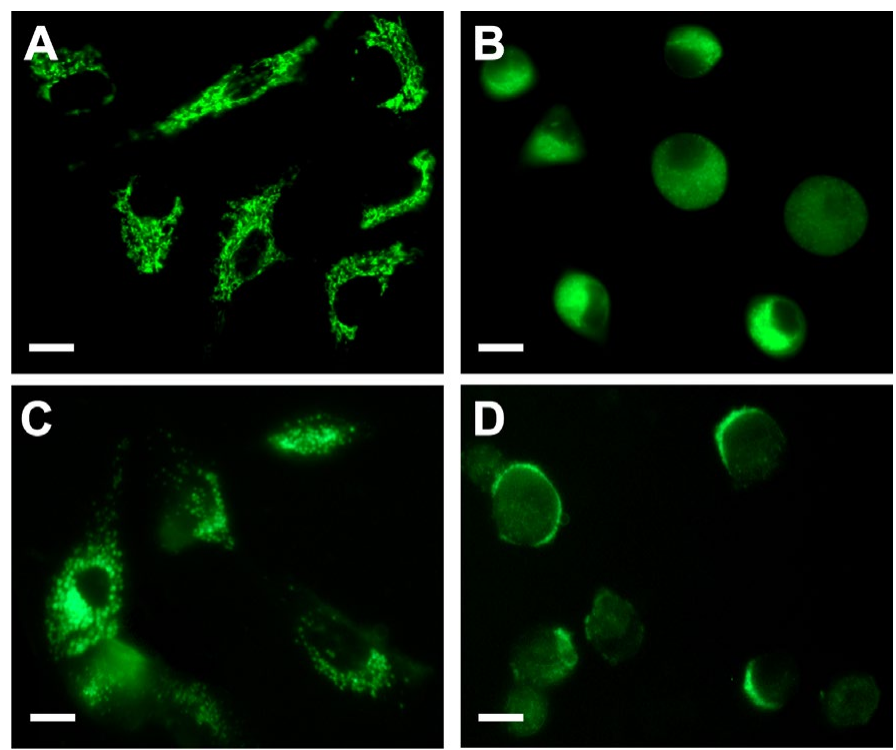

Figure 5. Fluorescent images of cells incubated with ALA and MitoTracker Green or LysoTracker Green before and after PDT.

Cells grown on coverslips were incubated $2.5 \mathrm{hr}$ with $1 \mathrm{mM}$ ALA ; then, $150 \mathrm{nM}$ MitoTracker Green (upper panel) or LysoTracker Green (lower panel) were added and the incubation continued for $30 \mathrm{~min}(\mathrm{~A}, \mathrm{C})$. Plates were irradiated for $10 \mathrm{~min}$ and examined $1 \mathrm{hr}$ later by fluorescence microscopy for organelle morphology (B, D). Scale bar $10 \mu \mathrm{m}$.

\section{Modulating agents affect differentially ALA-PDT-treated cells viability}

Porphyrin synthesis induced by exogenous administration of ALA and therefore, cell death after irradiation, can be regulated by several agents. As a first attempt to modify the outcome of PDT, we tested compounds whose effects on heme metabolism are well known. In this way, we verify the ability of our PDT system to be modulated by both increasing and decreasing porphyrin synthesis and/or cell death. As expected, SA, an inhibitor of 5-aminolevulinic acid dehydratase (the second enzyme of the heme biosynthetic pathway) significantly reduced ALA- induced porphyrin synthesis almost to control levels and also decreased cell death after illumination. On the other hand, the iron quelating agent Dfx enhanced cell death after ALA-PDT by lowering the available iron for the last step on heme biosynthesis and consequently inducing the accumulation of heme precursors (Figure 6).

Considering ROS are one of the earlier and major effectors of cell death induced by PDT, we tested several antioxidants and free radical scavenger on agents on their ability to modulate the treatment outcome; these compounds either neutralize or hijack ROS.

Various agents of distinct chemical nature with known antioxidant or ROS scavenger effect were employed: Man, Trp, GSH, Asc and Trx. To verify that none of them presented cytotoxicity/photoactivity, cell viability assays were performed incubating cells with different concentrations of the scavengers, ranging from 0.1 to $20 \mathrm{mM}$, and submitted to $10 \mathrm{~min}$ irradiation. We did not find any photosensitizing action by of the scavengers themselves, and none of the agents showed a any stimulation of cell death. Those concentrations presenting toxicity were discarded for the following experiments. The agents were tested for any alteration of porphyrin synthesis as well, but none of them significantly increased or decreased porphyrin levels (data not shown). Once this was checked, the ability of the compounds to modulate the viability of ALA-PDT treated cells was assessed in the whole selected concentration range.

To compare the effect of the compounds tested, we defined protection grade (PG) as the ratio between the cell survival after ALAPDT in the presence of the scavenger agent relative to survival in its absence, and those concentrations bearing the highest PG were selected to perform the following experiments (Figure 7). Maximum PGs were found at different concentrations, depending on the compound ( $1 \mathrm{mM}$ GSH, PG: $2.1 \pm 0.3 ; 10$ mM Man, PG: $1.1 \pm 0.1 ; 1 \mathrm{mM}$ Trp, PG: $1.7 \pm$ 0.1; $1 \mathrm{mM}$ Asc, PG: $2.6 \pm 0.1 ; 1 \mathrm{mM}$ Trx, PG: $3.5 \pm 0.1$ ), eeffects which can be attributed to the chemical nature and the particular quelating action of each agent.

\section{Scavenger agents protect against ALA-PDT-induced apoptosis}

To determine whether preincubation with these scavenger agents could modulate apoptotic cell death after ALA-PDT, double staining with acridine orange/ ethidium bromide was performed. 10 min ALAPDT, a higher light dose than the previously determined $\mathrm{LD}_{50}(7 \mathrm{~min})$, yielded $60.7 \pm 1.7 \%$ late apoptotic cells while early apoptotic cells reached $37.7 \pm 1.7 \%$, totalizing $98.4 \pm 3.4 \%$ apoptotic cells, indicating that the treatment was effective. Pre-incubation with scavenger agents considerably lowered apoptosis percentages down to $48.3 \pm 2.7 \%, 58.8$

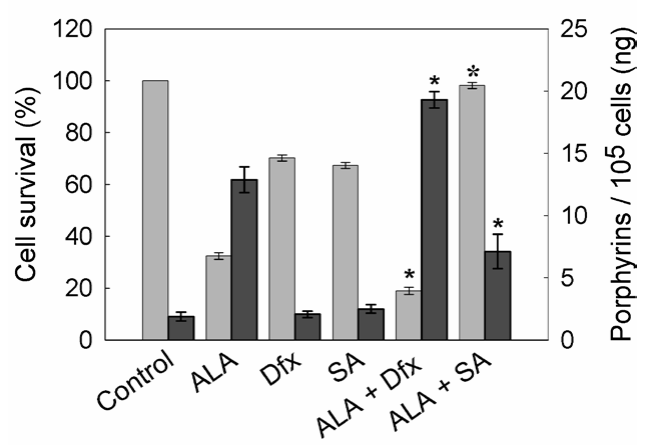

Figure 6. Porphyrin synthesis and cell survival after ALA-PDT in the presence of SA or Dfx.

Cells were incubated with $1 \mathrm{mM}$ Dfx or SA for $1 \mathrm{hr}$. Then, $1 \mathrm{mM}$ ALA was added and incubation continued for $3 \mathrm{hr}$. Cells were washed with PBS, covered with $2 \mathrm{ml} 5 \% \mathrm{HCl}$ and incubated at $37^{\circ} \mathrm{C}$ for 20 min to extract the intracellular porphyrins ( $\square$ dark grey bars). Cell survival ( $\square$ light grey bars) was determined at $1 \mathrm{hr}$ after PDT by the MTT assay. ( $\star$ :

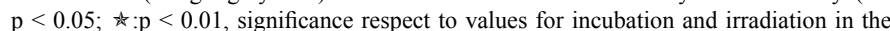
presence of ALA). 

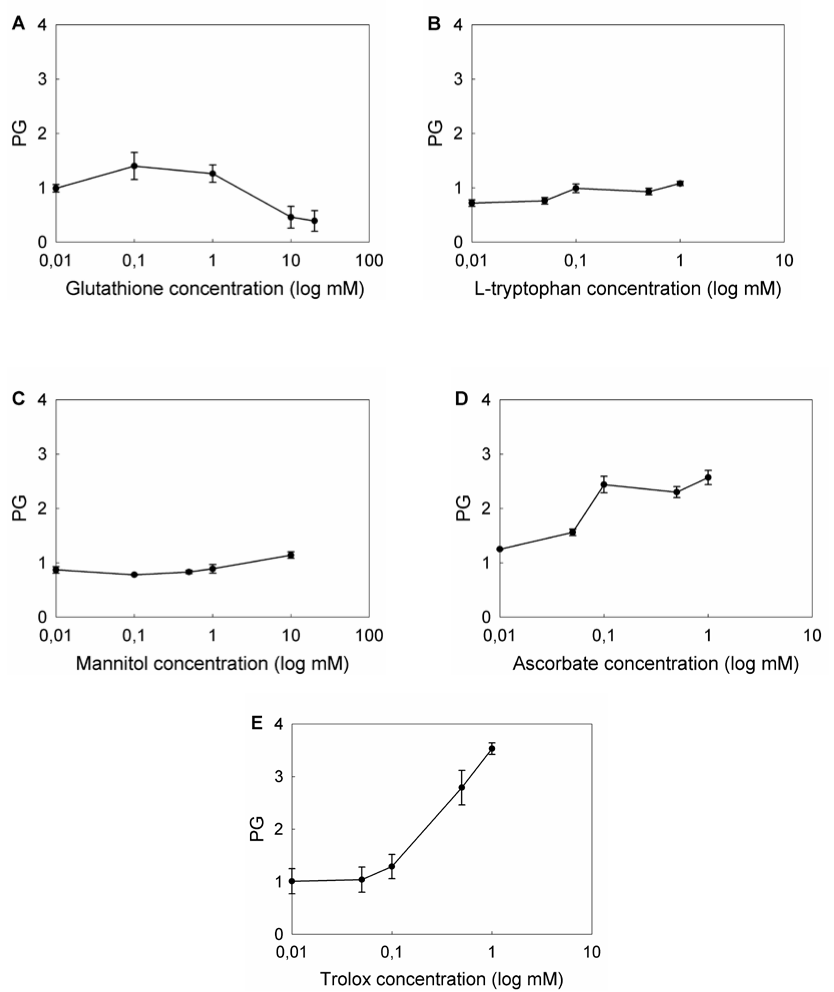

Figure 7. Effect of different concentrations of ROS scavenger agents on ALA-PDT. Cells were preincubated for $1 \mathrm{hr}$ with ROS scavengers at non-toxic, non-photoactive concentrations ranging from $0.01 \mathrm{mM}$ to $20 \mathrm{mM}$. ALA was added to a final concentration of $1 \mathrm{mM}$ and incubation continued for $3 \mathrm{hr}$. Cells were irradiated for $10 \mathrm{~min}$ and $1 \mathrm{hr}$ later the MTT assay was performed. Ratio between cell survival after ALA-PDT in the presence and in the absence of the scavenger agent was defined as Protection Grade (PG) for each scavenger (A: GSH; B: Trp; C: Man; D: Asc; E: Trx) $\pm 4.2,64.3 \pm 1.6 \%, 78.5 \pm 3.1 \%$ and $74.6 \pm 2.3 \%$ for Asc, Trx, Man, GSH and Trp, respectively (Figure 8 panel A, Figure 9A).

Similarly, preincubation with protective agents decreased the photodamage determined by Annexin V-FITC/ propidium iodide labelling. Again, Asc and Trx reduced significantly the signal for apoptotic cells from $26.8 \pm 4.2 \%$ to $3.15 \pm 0.35 \%$ and $1.2 \pm 0.5 \%$ respectively. Man, GSH and Trp lowered apoptosis levels to 9.95 $\pm 4.45 \%, 18.3 \pm 6.3 \%$ and $3.45 \pm 0.25 \%$ respectively (Figure 8 panel B, Figure 9B). These results confirm those previously obtained with morphological apoptosis staining, although Trp showed a higher protection when analyzed by flow cytometry.

These results imply that the extent of apoptosis was markedly reduced in scavengers pre-treated cells as compared to only ALAPDT treated cells. Moreover, cells pre-incubated with scavengers at the highest PG showed a FSC-SSC plot similar to those of control cells (Figure 3 panel F), indicating that cell morphology was apparently unaffected by ALA-PDT treatment when the protective agents are present during irradiation (Figure 8 panel C).

\section{Scavengers modulate cell death after ALA-PDT via selective reduction of ROS}

Production of several ROS after ALA-PDT can be detected by flow cytometry employing specific oxidizing fluorescent probes. Peroxides generation after ALA-PDT was determined by the use of $\mathrm{H}_{2}$-DCFDA, which is oxidized by peroxyl radicals, hydrogen peroxide and hydroxyl radicals. Singlet oxygen was detected thorough the selective oxidation of MVP. Superoxide anion production was monitored by the specific probe HE, and mitochondrial membrane potential (MMP) was analyzed by Rh123 which is taken up by polarized mitochondria.

Increased levels of reactive species were detected after ALA-PDT

\section{$10 \mathrm{~min}$ ALA-PDT}

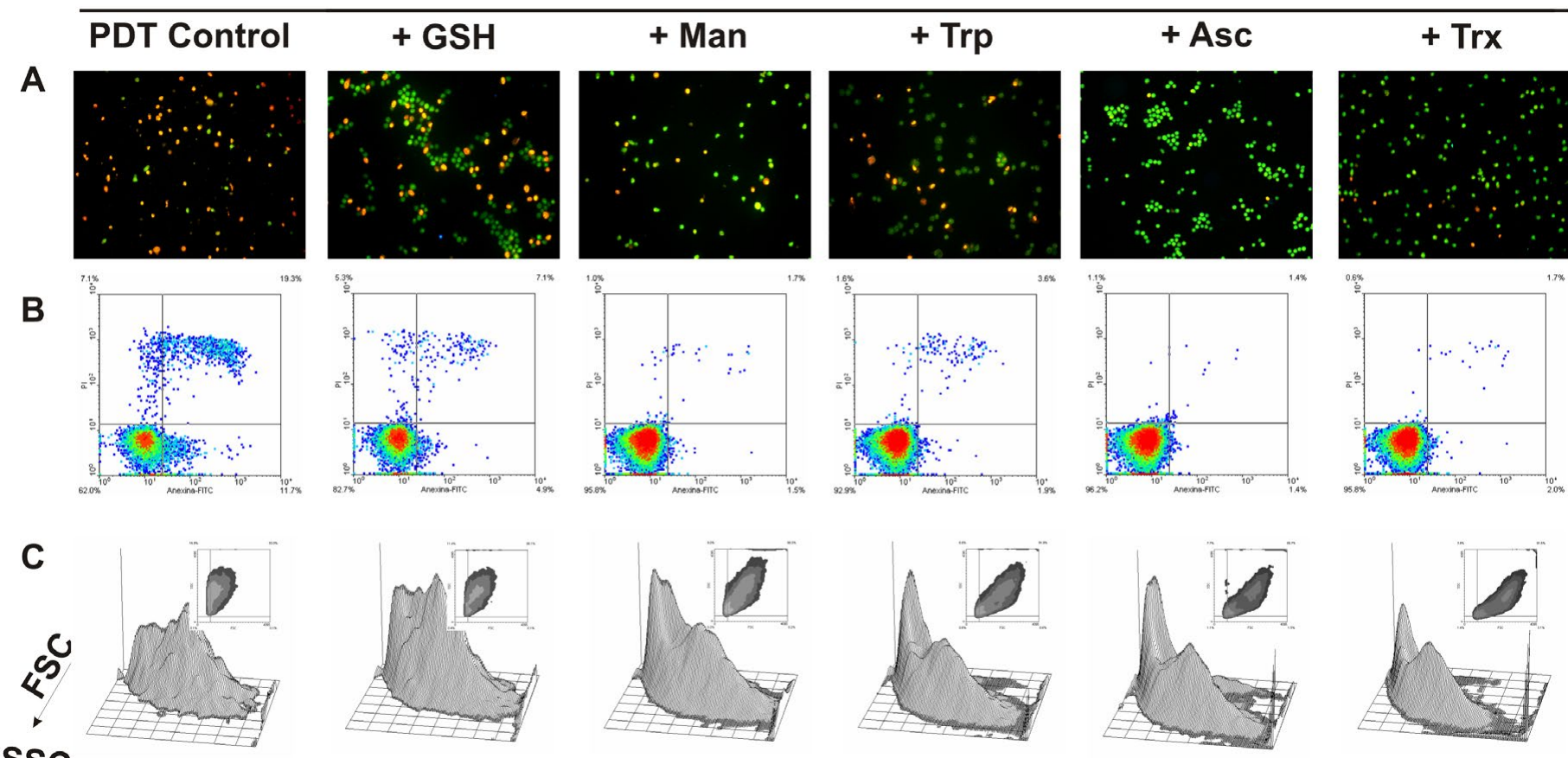

SSC

Figure 8. Cell morphology after 10 min ALA-PDT with $1 \mathrm{hr}$ pre-incubation with different ROS scavenger agents. Cells were pre-incubated $1 \mathrm{hr}$ with the scavengers at their highest PG concentration, then incubated with $1 \mathrm{mM} \mathrm{ALA}$ for $3 \mathrm{hr}$ and irradiated for $10 \mathrm{~min}$. After $1 \mathrm{hr}$, cells were trypsinized and stained with acridine orange and ethidium bromide (panel A) and visualized under fluorescence microscopy, or labelled with Annexin V-FITC / propidium iodide (panel B) and analyzed by flow cytometry. Cell size and granularity were assessed by light scattering by flow cytometry as well (panel C). 

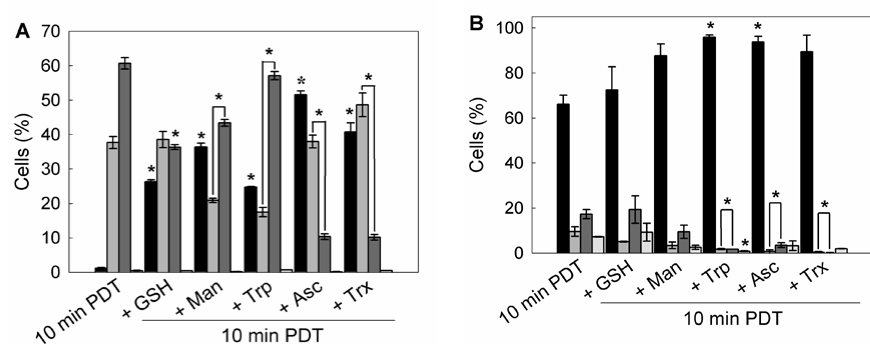

Figure 9. Quantification of viable, apoptotic and necrotic cells after $1 \mathrm{hr}$ pre-incubation with different ROS scavenger and 10 min ALA-PDT.

Cells were trypsinized $1 \mathrm{hr}$ after photodynamic treatment and stained with acridine orange / ethidium bromide and visualized under fluorescence microscopy (A), or labelled with Annexin V-FITC / propidium iodide and analyzed by flow cytometry (B).

Bar colors: black $\mathbf{m}:$ Viable cells; dark grey $\mathbf{m}$ : early apoptotic cells; light grey $\mathbf{m}$ : apoptotic cells; white $\square$ : necrotic cells) $(*: \mathrm{p}<0.05 ; *$ : $\mathrm{p}<0.01$, significance respect to $10 \mathrm{~min}$ ALAPDT values).
(Figure 10A). Maximum levels for both peroxides and singlet oxygen, were found at $10 \mathrm{~min}$ ALA-PDT $\left(\mathrm{H}_{2}\right.$-DCFDA positive cells: $69.3 \pm$ $5.6 \%$; MVP positive cells: $83.5 \pm 1.9 \%$ ), which may be due to the ROS instability and short life. In addition, with lower time doses, such as 5 min, levels were already high, according to the fast formation kinetics for ROS (data not shown). Superoxide anion reached its highest levels after 15 min irradiation (HE positive cells: $70.6,5 \pm 8.1 \%$ ) as well as cells with depolarized mitochondria ( $\mathrm{Rh} 123$ negative cells: $32.1 \pm 11.1 \%$ ).

Highly protective scavengers such as Asc and Trx were able to reduce peroxide radicals production (Asc and Trx pre-treated $\mathrm{H}_{2}-$ DCFDA positive cells: from $69.3 \pm 5,6 \%$ to $50.7 \pm 2.8 \%$ and $20.8 \pm 0,5 \%$ respectively), but only Asc was effective at reducing singlet oxygen and superoxide anion levels (Asc and Trx pre-treated MVP positive cells: from $83.5 \pm 1.9 \%$ to $25.4 \pm 5.2 \%$ and $73.6 \pm 3.4 \%$ respectively; Asc and Trx pre-treated HE positive cells: from $70.6,5 \pm 8.1 \%$ to $2.8 \pm$ $1.3 \%$ and $34.6 \pm 1.1 \%$ respectively). On the other hand, mitochondrial
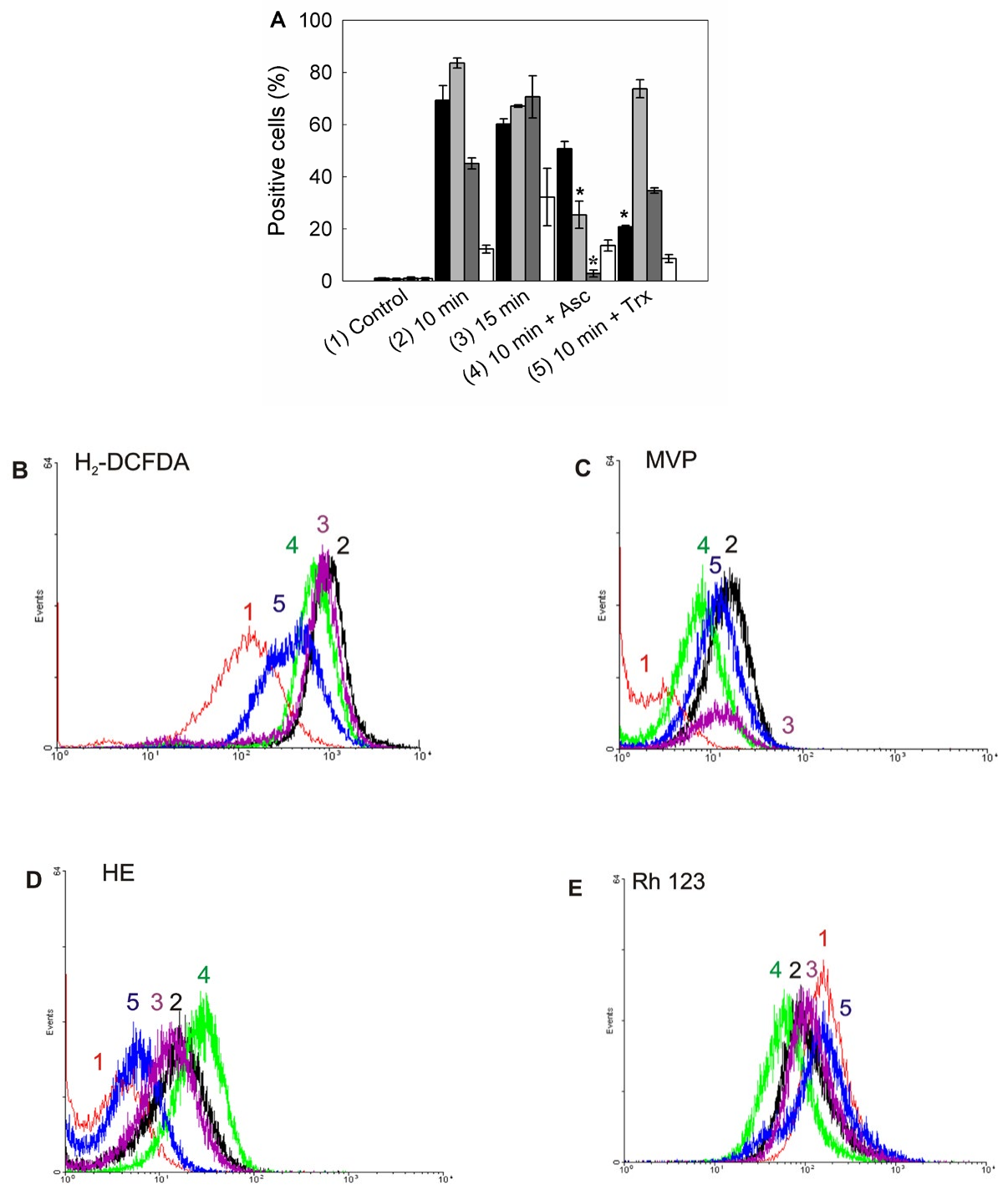

Figure 10. Intracellular ROS detection and mitochondrial membrane potential after ALA-PDT.

Positive cells were counted by flow cytometry for fluorescence of oxidized ROS specific probes (A). Bar colors: black $\mathbf{m}$ : $\mathrm{H}_{2}$-DCFDA; dark grey $\mathbf{m}$ : MVP; light grey $\mathbf{m}$ : HE; white $\square$ : Rh 123. Representative flow cytometry histograms for $\mathrm{H}_{2}$-DCFDA) (B), (MVP) (C), (HE) (D) and (Rh 123) (E) are shown. Cells were preincubated 1 hr with Asc and Trx at their highest PG concentration, incubated with $1 \mathrm{mM}$ ALA for $3 \mathrm{hr}$ and irradiated for 10 or $15 \mathrm{~min}$. After $1 \mathrm{hr}$ cells were trypsinized and loaded with $\mathrm{H}_{2}-\mathrm{DCFDA}(10 \mu \mathrm{M})$, MVP $(10 \mu \mathrm{M})$, HE $(2 \mu \mathrm{M})$ or Rh $123(10 \mu \mathrm{M})$ and incubated in the dark at $37^{\circ} \mathrm{C}$ for $30 \mathrm{~min}$. Samples were analyzed by flow cytometry. $(*: \mathrm{p}<0.05$; *: p $<0.01$, significance respect to 10 min ALA-PDT values). 
membrane depolarization was not significantly modified by scavenger pre-treatment. Incubation with scavengers before PDT resulted in light scatters similar to those of the control cells, indicating that cell morphology was slightly altered by the photodynamic treatment in the presence of scavengers (data not shown).

\section{Discussion}

With the exogenous administration of ALA, the negative feedback control that heme exerts over its own biosynthetic pathway is bypassed, and the accumulation of PpIX is induced. In malignant cells PpIX accumulation is more pronounced compared to their normal counterparts, and this is the rationale underlying ALA-PDT [16,17]. The advantages of PDT over conventional cancer therapies rely on its neat and selective tumor cell killing. Generation of ROS, with the ability to cause severe damage to vital organelles in a restricted time window and therefore, limiting cell damage to surrounding normal tissue, induces a cell death process just as neat as its oxidative initiation: apoptosis.

In this work, we found that lung cancer A549 cells showed a light dose-dependent response to ALA-PDT, and apoptosis appears as the most extensive cell death process taking place shortly after the treatment. Apoptotic cell morphology increases even after a minor ALA-PDT dose of $5 \mathrm{~min}$ and become predominant after $10 \mathrm{~min}$ of light exposure; necrosis percentages remained low even at the highest dose tested. Although PDT can produce apoptosis or necrosis, or a combination of the two mechanisms, which appears to be dependent on the dose of PDT, ALA-PDT is highly efficient to induce apoptosis often at low doses, implying that lower doses than those needed to produce necrosis are very effective in producing the desired cell killing results which, however, do not exclude autophagy and lysosomal apoptosis participation in cell killing [28-31].

ALA-induced PpIX localized mainly at mitochondria as seen in confocal images. Regarding organelle damage, and in consistence with the PpIX localization, mitochondria appeared to be seriously affected by 10 min ALA-PDT, which was expected not only for being the primary site of synthesis for PpIX, but also for being the site for the initiation of intrinsic apoptotic pathway. Localization of PS conditions the primary site for cell damage, since the photooxidative species formed after PDT have a short lifetime and diffusion distance [36,37]. As it was shown by loss of Rh 123 fluorescence in cells with depolarized mitochondria, MMP was increased after ALA-PDT, supporting the hypothesis for mitochondria as the site of cell death initiation. Lysosome disruption, although not a probable subcelular localization for PpIX, also emerged as a consequence of ALA-PDT. Most PS localizing at lysosomes can either delay or block the apoptotic program predisposing the cells to necrosis [26], which was not observed in our system. The lysosomal compartment is highly susceptible to oxidation and it was reported that permeabilization of lysosomal membranes does not precede MMP in cells photosensitized with hypericin [31].

Elucidating the behaviour of agents for PDT modulation is a useful tool to enhance cell death in malignant tissue and prevent it in normal cells [38]. It is expected that the iron chelator Dfx would enhance PDT-induced cell death by increasing heme precursors accumulation [39]. However, as an iron chelator, Dfx could also have reduced ROS generation by interfering with photochemical reactions. In our case, and in accordance to Fukuhara et al. report [39], Dfx was able to enhance cell death promoted by ALA-PDT; on the other hand, SA, by inhibiting the enzyme 5-aminolevulinic acid dehydratase, significantly reduced ALA- induced porphyrin synthesis almost to control levels and also decreased cell death after illumination.

Antioxidants, on the other hand, are primarily reducing agents prone to scavenge free radicals; consequently, antioxidants could compete with oxygen for quenching of the triplet sensitizer or can neutralize the generated reactive species, thus counteracting the effect of PDT [40-42].

There are several reports on the protective effect of certain antioxidants and reactive species scavengers against the lethal oxidative stress induced by photosensitization, however, their role is controversial as it was observed that in some cases they might increase, decrease or have no effect on PDT efficacy at all [41-45].

In general, antioxidants scavenging singlet oxygen (such as vitamin C) may decrease the effectiveness of PDT [24], while those increasing the amounts of singlet oxygen (such as mangostin) may exhibit a synergistic effect on PDT [46]. Many antioxidants can exhibit prooxidant activity, especially in the presence of catalytic metals; the later the antioxidant is added to the system, the more it is prone to act as a pro-oxidant. [47]. The potential therapeutic gain of the application of certain radical scavenger during PDT lies for example, in preventing side effects of PDT such as skin sensibility [48].

Whether certain antioxidants demonstrate anti or pro-oxidant behaviour depends on the molecular structure, concentration and timing of addition, among others [41]. Characterization of these agents, frequently used to clinically minimize photodamage to normal tissue, is an important stage before assuming what their action will be; this is the reason why investigation on antioxidant effects on PDT becomes relevant.

The results we presented indicate that all compounds tested showed at least a slight protective effect on ALA-PDT. In particular, Trx and Asc exhibited the greatest protection against cell death induction as well as prevention of ROS generation. Among the antioxidants tested, Asc plays a central role in the defense of free radical-induced cellular damage exhibiting also anticancerinogenic, antimutagenic, antibacterial, antiviral and anti-inflammatory effects [49]. It is able to react and reduce all physiologically relevant ROS and reactive nitrogen species, including superoxide, hydroperoxyl radicals, aqueous peroxyl radicals, singlet oxygen, ozone, nitrogen dioxide, nitroxide radicals, and hypochlorous acid [24]. This may be the reason why it was so effective at reducing both peroxide and singlet oxygen flow cytometry signals.

$\operatorname{Trx}$ is a water-soluble derivative of vitamin $\mathrm{E}$ and $\boldsymbol{\alpha}$-tocopherol analogue [50]; this main membrane-bound cellular antioxidant [51], in spite of having a broad spectrum of ROS scavenging, among which is hydrogen peroxide [52], was unable to significantly reduce the induction of singlet oxygen in our model. Besselnik et al. [53] reported protection of red blood cell suspension from photohemolysis against virus PDT inactivation by a combination of Tx and dipyridamole, however, Melnikova et al. [54] found an enhancement of metatetrahydroxyphenylchlorin (mTHPC)-sensitized PDT performed on HT29 human colon adenocarcinoma xenografts in nude mice injected with Tx.

GSH, Trp and Man increased viability by themselves or even in presence of light. Not only viability was increased by pre-incubation with scavengers, but also specific apoptotic features were prevented. Apoptosis assessed by flow cytometry detected higher percentages of viable cells in the presence of the scavengers compared to the controls incubated in the absence of the compounds. Protection by these agents 
was revealed in consistence with morphological staining-For Trp, higher protection when analyzed by flow cytometry was observed compared to the morphological features; GSH, and Man presented heterogeneous and low PGs, although they were able to significantly reduce the percentages of apoptotic cells.

These results indicate a grade of specificity for the scavenger agents, since their effects differ in the ROS species in which they have a significant action. Moreover, it is shown that ROS exert an important step in the early events following photodynamic treatment.

Many cancer treatments combine conventional therapies with complementary and alternative medicine therapies. Within this context, the ability of some antioxidants to modulate the outcome of PDT, improving its efficacy in tumoral tissue and decreasing photodamage to normal tissue, is a promising achievement for the use of this non-invasive therapy.

\section{Acknowledgements}

This work was supported by grants from University of Buenos Aires (UBACyT X 01/W521), the National Agency for Science and Technology (PICT-1806) and the National Research Council (CONICET, PIP 11220100100173). HF and AB hold the post of Scientific Researcher at the CONICET; MJT and BD are Fellows at the CONICET.

\section{References}

1. Dougherty TJ (2002) An update on photodynamic therapy applications. J Clin Laser Med Surg 20: 3-7.[Crossref]

2. Triesscheijn M, Baas P, Schellens JH, Stewart FA (2006) Photodynamic therapy in oncology. Oncologist 11: 1034-1044.[Crossref]

3. Yin R, Hamblin MR (2015) Antimicrobial Photosensitizers: Drug Discovery Under the Spotlight. CurrMed Chem 22: 2159-2185.[Crossref]

4. Juarranz A, Jaén P, Sanz-Rodríguez F, Cuevas J, González S (2008) Photodynamic therapy of cancer. Basic principles and applications. Clin Transl Oncol 10: 148-154. [Crossref]

5. Nyman ES, Hynninen PH (2004) Research advances in the use of tetrapyrrolic photosensitizers for photodynamic therapy. J Photochem Photobiol B 73: 1-28. [Crossref]

6. Neuhaus J, Schastak S, Berndt M, Walther J, Dietel A, et al. (2013) [Photodynamic therapy of bladder cancer. A new option]. Urologe A 52: 1225-1232.[Crossref]

7. Eljamel MS (2008) Brain photodiagnosis (PD), fluorescence guided resection (FGR) and photodynamic therapy (PDT): past, present and future. Photodiagnosis Photodyn Ther 5: 29-35.[Crossref]

8. Simone CB 2nd, Friedberg JS, Glatstein E, Stevenson JP, Sterman DH, et al. (2012) Photodynamic therapy for the treatment of non-small cell lung cancer. $J$ Thorac Dis4: 63-75.[Crossref]

9. Yano T, Hatogai K, Morimoto H, Yoda Y, Kaneko K (2014) Photodynamic therapy for esophageal cancer. Ann Transl Med 2: 29.[Crossref]

10. Soergel P, Hillemanns P (2010) Photodynamic therapy for intraepithelial neoplasia of the lower genital tract. Photodiagnosis Photodyn Ther 7: 10-14.[Crossref]

11. Wan MT, Lin JY (2014) Current evidence and applications of photodynamic therapy in dermatology. Clin Cosmet Investig Dermatol 7: 145-163.[Crossref]

12. Vohra F, Al-Kheraif AA, Qadri T, Hassan MI, Ahmed A, et al. (2015) Efficacy of photodynamic therapy in the management of oral premalignant lesions. A systematic review. Photodiagnosis Photodyn Ther 12: 150-159.[Crossref]

13. Choi YM, Adelzadeh L, Wu JJ (2015) Photodynamic therapy for psoriasis. $J$ Dermatolog Treat 26: 202-207.[Crossref]

14. Baltazar LM, Ray A, Santos DA, Cisalpino PS, Friedman AJ, et al (2015) Antimicrobial photodynamic therapy: an effective alternative approach to control fungal infections. Front Microbiol 6: 202. [Crossref]

15. Kuzyniak W, Ermilov EA, Atilla D, Gürek AG, Nitzsche B, et al. (2016) Tetra- triethyleneoxysulfonyl substituted zinc phthalocyanine for photodynamic cancer therapy. Photodiagnosis Photodyn Ther 13: 148-157.[Crossref]

16. Fukuda H, Casas A, Batlle A (2006) Use of ALA and ALA derivatives for optimizing ALA-based photodynamic therapy: a review of our experience. J Environ Pathol Toxicol Oncol 25: 127-143.[Crossref]

17. Batlle AM (1993) Porphyrins, porphyrias, cancer and photodynamic therapy--a model for carcinogenesis. J Photochem Photo Biol B 20: 5-22.[Crossref]

18. Friesen SA, Hjortland GO, Madsen SJ, Hirschberg H, Engebraten O, et al. (2002) 5-Aminolevulinic acid-based photodynamic detection and therapy of brain tumors (review). Int J Oncol 21: 577-582.[Crossref]

19. Dunn J, Lovat L (2008) Photodynamic therapy using 5-aminolaevulinic acid for the treatment of dysplasia in Barrett's oesophagus. Expert Opin Pharmacother 9: 851-858. [Crossref]

20. Recio ED, Zambrano B, Alonso ML, de Eusebio E, Martín M, et al. (2008) Topical 5 -aminolevulinic acid photodynamic therapy for the treatment of unilesional mycosis fungoides: a report of two cases and review of the literature. Int J Dermatol 47: 410413.[Crossref]

21. Bissonnette R, Maari C, Nigen S, Provost N, Bolduc C (2010) Photodynamic therapy with methylaminolevulinate $80 \mathrm{mg} / \mathrm{g}$ without occlusion improves acne vulgaris. $J$ Drugs Dermatol 9: 1347-1352.[Crossref]

22. Nie Z, Bayat A, Behzad F, Rhodes LE (2010) Positive response of a recurrent keloid scar to topical methyl aminolevulinate-photodynamic therapy. Photodermatol Photoimmunol Photomed 26: 330-332.[Crossref]

23. Hillemanns P, Einstein MH, Iversen OE (2015) Topical hexaminolevulinate photodynamic therapy for the treatment of persistent human papilloma virus infections and cervical intraepithelial neoplasia. Expert Opin Investig Drugs 24: 273-281. [Crossref]

24. Frank J, Flaccus A, Schwarz C, Lambert C, Biesalski HK (2006) Ascorbic acid suppresses cell death in rat DS-sarcoma cancer cells induced by 5 -aminolevulinic acidbased photodynamic therapy. Free Radic Biol Med 40: 827-836.[Crossref]

25. Mikes J, Kleban J, Sacková V, Horváth V, Jamborová E, et al (2007) Necrosis predominates in the cell death of human colon adenocarcinoma HT-29 cells treated under variable conditions of photodynamic therapy with hypericin. Photochem Photobiol Sci 6: 758-766.[Crossref]

26. Oleinick NL, Morris RL, Belichenko I (2002) The role of apoptosis in response to photodynamic therapy: what, where, why, and how. Photochem Photobiol Sci 1: 1-21. [Crossref]

27. Kessel D (2015) Apoptosis and associated phenomena as a determinants of the efficacy of photodynamic therapy. Photochem Photobiol Sci 14: 1397-1402.[Crossref]

28. Kessel D, Vicente MG, Reiners JJ Jr (2006) Initiation of apoptosis and autophagy by photodynamic therapy. Autophagy 2: 289-290.[Crossref]

29. Buytaert E, Dewaele M, Agostinis P (2007) Molecular effectors of multiple cell death pathways initiated by photodynamic therapy. Biochim Biophys Acta 1776: 86-107. [Crossref]

30. Reiners JJ Jr, Agostinis P, Berg K, Oleinick NL, Kessel D (2010) Assessing autophagy in the context of photodynamic therapy. Autophagy 6: 7-18.[Crossref]

31. Kessel D, Luo Y, Mathieu P, Reiners JJ Jr (2000) Determinants of the apoptotic response to lysosomal photodamage. Photochem Photobiol 71: 196-200.[Crossref]

32. Piette J, Volanti C, Vantieghem A, Matroule JY, Habraken Y, et al. (2003) Cell death and growth arrest in response to photodynamic therapy with membrane-bound photosensitizers. Biochem Pharmacol 66: 1651-1659.[Crossref]

33. Wei MF, Chen MW, Chen KC, Lou PJ, Lin SY, et al (2014) Autophagy promotes resistance to photodynamic therapy-induced apoptosis selectively in colorectal cancer stem-like cells. Autophagy 10: 1179-1192.[Crossref]

34. Washbrook R, Fukuda H, Battle A, Riley P (1997) Stimulation of tetrapyrrole synthesis in mammalian epithelial cells in culture by exposure to aminolaevulinic acid. $\mathrm{Br} J$ Cancer 75: 381-387.[Crossref]

35. Denizot F, Lang R (1986) Rapid colorimetric assay for cell growth and survival Modifications to the tetrazolium dye procedure giving improved sensitivity and reliability. J Immunol Methods 89: 271-277.[Crossref]

36. Dysart JS, Singh G, Patterson MS (2005) Calculation of Singlet Oxygen Dose from Photosensitizer Fluorescence and Photobleaching During mTHPC Photodynamic Therapy of MLL Cells. Photochem Photobiol 81: 196-205.[Crossref] 
Teijo MJ (2016) Modulation of 5-Aminolevulinic acid mediated photodynamic therapy induced cell death in a human lung adenocarcinoma cell line

37. Moan J, Berg K (1991) The photodegradation of porphyrins in cells can be used to estimate the lifetime of singlet oxygen. Photochem Photobiol 53: 549-553.[Crossref]

38. Kamat JP, Devasagayam TP (2000) Oxidative damage to mitochondria in normal and cancer tissues, and its modulation. Toxicology 155: 73-82.[Crossref]

39. Fukuhara H, Inoue K, Kurabayashi A, Furihata M, Fujita H, et al ( 2013) The inhibition of ferrochelatase enhances 5-aminolevulinic acid-based photodynamic action for prostate cancer. Photodiagnosis Photodyn Ther 10: 399-409.[Crossref]

40. Friaa O, Maillard P, Brault D (2012) Reaction of the m-THPC triplet state with the antioxidant Trolox and the anesthetic Propofol: modulation of photosensitization mechanisms relevant to photodynamic therapy? Photochem Photobiol Sci 11: 703-714. [Crossref]

41. Jakus J, Farkas O (2005) Photosensitizers and antioxidants: a way to new drugs? PhotochemPhotobiolSci4: 694-698.[Crossref]

42. Lu Z, Tao Y, Zhou Z, Zhang J, Li C, et al (2006) Mitochondrial reactive oxygen species and nitric oxide-mediated cancer cell apoptosis in 2-butylamino-2 demethoxyhypocrellin B photodynamic treatment. Free Radic Biol Med 41: 15901605.[Crossref]

43. Gederaas OA, Schønberg SA, Ramstad S, Berg K, Johnsson A, et al. (2005) Cell specific effects of polyunsaturated fatty acids on 5-aminolevulinic acid based photosensitization. Photochem Photobiol Sci 4: 383-389.[Crossref]

44. Perotti C, Casas A, Del C Batlle AM (2002) Scavengers protection of cells against ALA-based photodynamic therapy-induced damage. Lasers Med Sci 17: 222-229. [Crossref]

45. Stockert JC, Herkovits J (2003) Photodynamic toxicity and its prevention by antioxidative agents in Bufoarenarum embryos. Toxicology 192: 211-218.[Crossref]
46. Sun D, Zhang S, Wei Y, Yin L (2009) Antioxidant activity of mangostin in cell-free system and its effect on K562 leukemia cell line in photodynamic therapy. Acta Biochim Biophys Sin (Shanghai) 41: 1033-1043.[Crossref]

47. Buettner GR, Jurkiewicz BA (1996) Catalytic metals, ascorbate and free radicals: combinations to avoid. Radiat Res 145: 532-541.[Crossref]

48. Hogikyan ND, Hayden RE, McLear PW (1991) Cutaneous photoprotection using a hydroxyl radical scavenger in photodynamic therapy. Am $J$ Otolaryngol 12:1-5. [Crossref]

49. Nichenametla SN, Taruscio TG, Barney DL, Exon JH (2006) A review of the effects and mechanisms of polyphenolics in cancer. Crit Rev Food Sci Nutr 46: 161-183.[Crossref]

50. Poljsak B, Raspor P (2008) The antioxidant and pro-oxidant activity of vitamin C and trolox in vitro: a comparative study. $J$ Appl Toxicol 28: 183-188.[Crossref]

51. Wu TW, Hashimoto N, Wu J, Carey D, Li RK, et al. (1990) The cytoprotective effect of Trolox demonstrated with three types of human cells. Biochem Cell Biol 68: 11891194.[Crossref]

52. Hamad I, Arda N, Pekmez M, Karaer S, Temizkan G (2010) Intracellular scavenging activity of Trolox (6-hydroxy-2,5,7,8-tetramethylchromane-2-carboxylic acid) in the fission yeast, Schizosaccharomyces pombe. J Nat Sci Biol Med 1: 16-21.[Crossref]

53. Besselink GA, van Engelenburg FA, Ebbing IG, Hilarius PM, de Korte D, et al (2003) Additive effects of dipyridamole and Trolox in protecting human red cells during photodynamic treatment. Vox Sang 85: 25-30.[Crossref]

54. Melnikova VO, Bezdetnaya LN, Brault D, Potapenko AY, Guillemin F (2000) Enhancement of meta-tetrahydroxyphenylchlorin-sensitized photodynamic treatmen on human tumorxenografts using a water-soluble vitamin $\mathrm{E}$ analogue, Trolox. Int $J$ Cancer 88: 798-803.[Crossref]

Copyright: (C)2016 Teijo MJ. This is an open-access article distributed under the terms of the Creative Commons Attribution License, which permits unrestricted use, distribution, and reproduction in any medium, provided the original author and source are credited. 